\title{
Ideology and moral: relationship of norm and ideal in the light of synergetic philosophy of history
}

\author{
Sergey Busov ${ }^{1, *}$, Mariya Zobova ${ }^{2}$, Alexey Rodukov ${ }^{2}$ \\ ${ }^{1}$ St. Petersburg National Research University of Information Technologies, Mechanics and Optics \\ (University ITMO), Saint Petersburg, Russia \\ ${ }^{2}$ St. Petersburg State University of Telecommunications after prof. M.A.Bonch - Bruyevich (SUT \\ after prof. M.A.Bonch-Bruevich, Saint-Petersburg), St. Petersburg, Russia
}

\begin{abstract}
The formation of notions about the mechanism of transition from the social order to the chaos and vice versa - from the chaos to a new order, represented by the synergetic philosophy of history, which is entirely based on the ideas of V.P. Branskiy, allows us to take a fresh look at the process of changing value systems in society. It is based on the process of changing ideals. The social ideal aims to overcome the contradictions of life. However, when its main function is implemented, some contradictions disappear, but others appear. The selection of viable ideals leads us only to a temporary softening of social contradictions: the implementation of new ideals deduces the society from the deadlock, but at the same time, it forms the conditions for new contradictions and new crisis in the new system of values. The study of the process of selforganization of ideals and values allowed the St. Petersburg school of social synergetics to discover the operation of law of correlation of the standards of behavioral stereotype to the standards of ethical ideal. The study of this law serves as a system-forming element in the study of the ideology of society, it allows us to understand why an adequate form of existence of such cultural universals as freedom, goodness, beauty, truth, besides the ideal, is also the norm - as value and the regulator of relations.
\end{abstract}

\section{Introduction}

We live in a complex and rapidly changing world. Theoretical comprehension of social processes, represented by the synergetic philosophy of history, entirely based on the ideas of V.P. Branskiy (1930-2017), allows us to understand the mechanism of transitions from social order to chaos and vice versa from chaos to a new order. Such transitions are made in all spheres of social life, but in this case we are interested in the process of changing value systems. In order to explain the evolution of culture, it is necessary to identify the general patterns of the development of social ideals that underlie the value orientations of people. The concept of an ideal is expressed in the concept of an object devoid of contradictions. Hence it follows that the main function of the ideal in the process of its realization is

\footnotetext{
*Corresponding author: swbusoff@mail.ru
} 
associated with the construction of such an object. The social ideal is designed to remove the contradictions of life, however, with its implementation, some contradictions disappear, but others arise. Any ideal sooner or later becomes obsolete and leaves the historical scene. A new ideal, which, of course, is not the only one that claims to dominate, arises through the mental liberation of society from the system of contradictions. According to D.A. Zhurenkov, the selection of viable ideals leads to a temporary softening of social contradictions, softening of the crisis and, by the implementation of new ideals, brings society out of the impasse, but at the same time, it "brings in the new unified system of values the beginnings of new contradictions and the embryo of future discord" [1]. Social crises also have a pronounced existential coloring and are associated with the meanings of people's lives.

If the concept of truth is not capable of answering the question about the meaning of human life, then the ideal within a certain system of values is directly responsible for this question, which is clearly demonstrated by the history of society. The life and activity of people, illuminated by a certain ideal, are filled with deep meaning until this ideal is replaced by another. With the decline of the dominant ideal, the activities of many people lose their former meaning.

But only a new viable ideal and a new ideology can bring an individual out of the crisis, but, unfortunately, neither truth nor science can claim this role. However, ideology needs truth in order to consolidate its ideal and at the same time it opposes science in the struggle for domination over the minds of people, claiming the role of a universal means for solving any problems. As E.V. Shcherbakova, leader of the St. Petersburg school of social synergetics, correctly noted that the meaning of both history and individual life is revealed not by science, but by ideology, but to understand how she does is possible only with the help of science [2].

\section{Materials and Methods}

Ideological contradictions are the mirror of all social problems. An important question, in this regard, remains the question how social evolution absorbs the universal human content of cultural values in the stream of people's value orientations at different historical times and levels of social relations. The answer suggests itself: an adequate form of existence of cultural universals such as freedom, goodness, beauty, truth, in addition to the ideal - with its inherent functional wealth, is the norm (as a value in general and a regulator of relations, in particular). Thus, freedom appears as a norm (most often - moral) and as an ideal, i.e. there is a relationship between being and what should be in freedom as a source of development of relations. The same applies to other cultural universals - truth, goodness, beauty. Yet the universal of freedom occupies a special place; it is a kind of universal equivalent in the world of cultural values, leading to the formation of a norm as a range of adaptive activity of the subject, directing a person, guided by an ideal, to transform himself and his environment. Another aspect is the contradiction between everyday life and ideology. Ideology seeks to overcome, destroy the world of everyday life forms based on the norms and values corresponding to them, and replace them, through sacrificial rejection of them for the sake of a "bright future".

In order to form a moral assessment of people's actions, it is necessary to have an ethical criterion, a certain integrative standard of value, which, being the core of the system of ethical standards, creates its integrity. Such a standard is an ethical ideal (as a rule, an ideal person) as a subject of obligation. The moral aspect of the ideal person assumes that over the area of his activity, which is determined by the formula: "I do everything what I want and can," dominates the area "I do what I have to do." The ethical ideal, therefore, is associated with obligation, but not only, but also with what a person can do in specific 
conditions, i.e. connected with existence. According to the apt expression of V.P. Bransky, the opposition of the real and the proper is formed, expressed by the opposition of truth and ideal [3].

All the diversity of views on life and on the conformity of norms and ideals is carried by ideology. Delving deeper into the content of ideology, it should be recognized that the core of this social phenomenon is the ratio of norm and ideal. Ideology has three points of support - the ideal, the canon and the ritual - and these latter are dressed in a special allegorical "suit", the elements of which are symbols, images, myths and cults. Only in such a "suit" does the ideal become universally valid, takes possession of the mass and descends from "heaven" to earth, S.S. Horuzhy [4]. The listed features of ideology are a common place for all any significant ideological attitudes, ideological systems, value orientations that unite people, direct and motivate them to implement any significant social, political, cultural or technical project. So, for example, the generally recognized "theoretical" part of the ideology of Catholicism is the treatises "On the City of God" by Augustine and "Sum of theology" by Thomas Aquinas, in which the religious ideal is not only colorfully drawn, but also philosophically substantiated. There, the ideal is represented by an ideal person - Jesus Christ, and is also expressed in the person of the saints of the Christian Church, S.S. Horuzhy [5]. More straightforward and at the same time more perfect than in world religions, the ideal, as a phenomenon of the spiritual life of man, is apparently not represented anywhere. And where there is a secular ideology and a secular ideal is clearly expressed, they invariably have a reflection of religiosity and holiness. This "sinned" not only the communist ideology, but even the Nazi and ISIS. The last two are prohibited in the Russian Federation, however, it is difficult to talk about their spirituality in view of the strong discrepancy between the norm and the ideal: the social norm they introduce does not allow a person to successfully adapt to the proposed conditions, and the ideal ignores the possibility of his self-realization, requiring excessive sacrifices. As history shows, no ideal can be realized without making sacrifices on its "altar", without the sacrifice procedure, which becomes the norm of behavior. It is in this aspect that one can find a pronounced pragmatic attitude of people to the ideal, as well as find signs of a utopian principle in its content. We are talking about the problem of translating the ideal into reality, for which sacrifice is morally necessary and inevitable.

The correlation between the ideal and the truth reveals a number of significant functional differences. So, the difference between the ideal and the truth is emphasized in the concept of faith, which belongs not only to the field of religion, but also to the field of science, as a complex of expectations of varying degrees of probability. If the concept of truth is traditionally associated with logical reasoning, proof and experiment, then the ideal includes faith and sacrifice. In true (first of all, scientific) knowledge, faith is secondary, since scientific faith is based on rational arguments. The ideal, on the other hand, is characterized by the priority of faith ("I know because I believe," as Thomas Aquinas argued). Ideological faith is irrational because it is based, rather, on the desires and dreams of a person. The connection between ideology and the unconscious is obvious: the concept of "illusory consciousness" by K. Marx and the theory of the unconscious by S. Freud, say that the individual is not aware of the reasons for his beliefs. Likewise, a person in an adult state does not know why he became like this and not different.

Unlike a scientist who believes in hypotheses because they are based on scientific facts, a person who does not have this kind of scientific background believes in something only on the basis of broad, often unsystematic and prejudicial, worldview attitudes. Scientific faith, as a special type of secular faith, although not reducible to it, presupposes such a psychological state of a person in which conviction in truth arises, i.e. in accordance with the subjective image of the investigated object. This is how the criterion for assessing knowledge is formed, and conviction in the truth arises only if there is evidence and 
experiment. Consequently, scientific faith is not knowledge, but an assessment of the information obtained through evidence and experiment. Scientific faith is not truth, but is closely related to it. On the contrary, any ideological, whether religious or secular, faith is associated with the concept of the ideal; here a person is convinced that the image corresponds not to the object being studied, but to his desire. Therefore, ideological faith is irrational, since it presupposes sacrifice, not proof, as a strengthening, i.e. a special form of service to the ideal and emotional attachment to it. The victim, more precisely, the degree of its magnitude, the level of affection, is a criterion for assessing the conviction in the ideal and loyalty to it.

\section{Results}

The cultural significance of moral norms associated with an ethical ideal is that they are a value. Values are produced and reproduced, more precisely, they represent "the realization of the pragmatic aspect of a certain ideal," notes V.P. Bryansky [5]. There are fundamental, archetypal, "substantial" values common to people. They are invariant and absolute in the sense in which the unity of the origin and evolution of mankind is absolute. But they are relative in terms of their historically specific origin and expression. The unity of human values is ensured by the "accuracy" of their reproduction and the impossibility of such kind of macromutations, which would lead to serious changes in the "value matrix", entailing, for example, the substitution of the essence of maternal love for a child, the father's responsibility for preserving the family, the meaning of the biblical "ten commandments", the concept of "karma", etc. The emergence of a social norm marked the transition from an instinctive form of hominid behavior to a rational one. A paradoxical situation has come true: what is a pathology for a biological system becomes the norm for a person as a biosocial being. The point is that a person can be guided by an ideal (in fact, an illusion of reality), and an animal that confuses illusion with reality, as a rule, dies. The social norm indicates those boundaries within which the subject retains his essence, remaining himself. At the same time, the norms are characterized by amplitudes near a certain optimum, including what was described above by us as a value matrix. Now this is especially noticeable when analyzing the "reassessment of values" in those countries where revolutions have recently taken place ("revolution of dignity" in Ukraine, "Arab Spring", etc.). So, in Ukraine, a split of society took place - into those who preserved the social norm, defended it, defended it at the cost of considerable sacrifices (talking about the residents of Donbass) and those who radically changed the value matrix (talking about many residents of western and central Ukraine).

There are so-called conservative values and norms that can be called "old", but many of them are not at all obsolete and have lost their relevance; it should be emphasized that such values are often more alive and more expensive than other new, early-maturing values and norms of behavior. The renewal of the old "value baggage" and its new revaluation is a common historical fact. Thus, during the "thaw" in the Soviet Union, the return to the "Leninist norms of party leadership" was perceived as a turn to new values, and during the Perestroika period - as a relic of the past. This is evidence not only of the "turning around" of the same ideals, but also an indication of their "earthly roots", since the change of ideals depends on which of them wins. Further, the idea of "exporting revolution" was considered very progressive during the Soviet Union - with its help the struggle for the liberation of countries from colonial dependence was fought. The era and the idea of exporting models of a political regime have changed, for example, the idea of "exporting democracy", so beloved by the United States today, began to be assessed by us as extremely "reactionary", since it is associated with a violation of the country's sovereignty. 


\section{Discussion}

In modern, first of all, Western culture, there is an identification of the concepts of truth and ideal, and, consequently, truth and ideology, since ideology is the doctrine of the ideal: they should not be confused. Therefore, it is inappropriate to speak of a scientific ideal; one should speak of a scientific study of the ideal. Such an illegal substitution of concepts leads to the deconstruction of scientific truth and its substitution with various surrogate forms of ideals. There is a kind of return to the famous thesis of Protagoras, according to which truth is nothing more than my individual perception of the world [6]. Truth, as the coincidence of knowledge with reality, must be objective.

The "Western" interpretation of neoliberal ideology deforms the value matrix, and, like any ideology, it tends to absolutize some values, neglecting others. This applies, first of all, to the liberation of the individual from coercive imperatives from the state, as well as from legal and moral norms that protect the institutions of the family and marriage. On this basis, modern libertalism is born - this is an extremely awkward application of classical liberalism - a kind of "philosophy of law" aimed at not observing any rules at all. According to K. Steckl, it is based on the principle of self-determination, which is the basis of the right to freedom, life, property [7]. To dispose of yourself as you please is the ideal of many ideological anarchists. Western "human rights defenders", who until recently defended traditional religious and secular ideals, now openly encourage everything that leads to their destruction: propaganda and sanctification of same-sex marriage, unbridled encouragement of LGBT communities, gender reassignment, etc. Such "practices" lead to dismemberment families and, as a result, to manage disoriented ("not remembering their kinship") individuals who have lost their identity. They are left without their natural biological characteristics: without sex, without family, without marriage and without love. R.V. Mikhailov notes that "the struggle between two worlds, two ideologies" did not disappear after the collapse of the Soviet Union [8]. Modern Russia, like "Soviet communism" with its "moral code of the builder of communism", relies on conservative values and acts as the antithesis of Western postmodernism and deconstructivism: imperial "grand style" versus "simulacra" of Western decadence. A.M. Makhler believes that sacrificing conservative values entails an inevitable punishment - lust instead of love, cohabitation instead of family, extinction instead of a healthy fullness of being [9].

Ethical (moral) assessment of a particular individual, as a rule, is carried out by correlating his actions with the actions of an ideal person (such are mythological heroes, gods of world religions, saints, knights without fear and reproach, and, finally, real professionals). It is customary to evaluate the orientation of a specific deed towards the ethical ideal in the category of good (good deed), and distance from the ideal (direction from it) is assessed as evil. Since society is heterogeneous, each of its strata has its own behavioral stereotype and its own ethical ideal, "complementary" (the expression of the Russian ethnographer L.N. Gumilyov) to each other. However, this does not mean that, according to S. Fufaev, there is little in common in the ethical ideals of different peoples and social groups, on the contrary, their general content increases with the course of history [10]. The action of the law of relevance, developed within the framework of the St. Petersburg school of social synergetics, is associated with the degree to which the old stereotype corresponds to the new ideal. In-depth consideration of this issue leads to the identification of the following tendencies: there is a close interaction of the process of differentiation and integration of ethical ideals and the differentiation and integration of stereotypes of behavior - within the limits of the restrictions imposed by the law of relevance (compliance of stereotype standards with the standards of ethical ideal) in relation to both individual individuals and ethnic, professional and other groups, which leads to the selection of an "optimal pair" - an "old" stereotype and a "new" ideal. J.K. 
Larcher notes that this or that social stratum (community, group), which has its own stereotype of behavior and its own ethical ideal, for example, being within the framework of the modern technosphere, evaluates itself through the ideology of the technosphere, i.e. through the ratio of its inherent norm and ideal [11].

The stereotypes of labor behavior carry different functions, such as structuring, identifying, adapting, regulating functions, to each of which should be tied not so much to a scientific as to an ideological characteristic. Let it be students, university professors or workers employed in the field of material production, they will all have a certain behavioral stereotype (what has developed in practice), a certain moral standard of assessment (what is expressed in an ethical or legal norm), and what the prevailing social ideal requires of them. In other words, it has its own ideology. In the process of work or study, the selection of the most acceptable forms of behavior in a particular sphere of society takes place. In our time, the technosphere penetrates into all spheres of society, therefore, being within its framework requires an appropriate ideology, namely, the correspondence of the technical (professional) stereotype of behavior and the ethical (social) ideal. The stereotype of behavior is associated with conformism, that is, with adaptation to the natural and social environment; the ideal, however, is related with transformism, that is, with the transformation of both one and the other. The unity (synthesis) of the above aspects of labor activity can be effective if their harmonious proportion has arisen; according to the law of necessary diversity, or, in other words, the law of "restricting diversity", there is a relationship between internal diversity and the efficiency of system management. From this it follows, A.V. Nesteruk writes that intensive innovations, such as the above practices of neoliberalism and libertalism, are capable of destroying the manageability, and therefore stability, of any social system [12].

Freedom and responsibility in their unity can be represented as a difference of priorities, voluntarily and consciously accepted by the subject of choice. Freedom presupposes the priority of law, and responsibility the priority of duties in relation to rights. It should be understood that the right is only realizable when it is filled with fulfilled duties, while, in turn, the duties must correspond to the hierarchy of rights. For example, the rights of a bachelor student correspond to a set of duties, and, having fulfilled the necessary duties, having thereby won the right to transfer to a master's degree, the student receives a new set of duties corresponding to the new hierarchy of rights. If we look at this through the prism of the law of conformity of stereotype standards to the standards of the ethical ideal, it turns out that in order to adapt to new conditions, it is necessary to change the stereotype of behavior, and for this it is necessary to be guided by a new ideal. In the process of changing the stereotype, a norm of adaptation arises, being in which a person (in this case, a student) is faced with a new set of responsibilities. Further, in the process of fulfilling these duties, it becomes clear: does the specified norm of adaptation correspond to the level of rights and obligations? According to M.J. Hoon, the level of inconsistency generates the need for a new ideal [13].

Since we are more interested in the scientific interpretation of ideology, considered in the aspect of the relationship between the norm and the ideal in it, in the description of the norm, we should correlate the measure of order and the measure of chaos (in relation to the society of anarchism and totalitarianism). That is, aspects of the stability of the norm, the reproduction of its main characteristics, as well as the aspect of its instability, variability; and in relation to the ideal is its pragmatic and utopian aspects and their relationship. The system-forming center of such research should be the law (regularity) of the conformity of the stereotype standards to the standards of the ethical ideal, which would make it possible to explain the known facts in a given research subject area and predict the unknown. According to S.V. Busov, the study of the named regularity serves as a system-forming 
factor in the study of the ideology of society, it allows us to link together different methodological aspects of such a complex subject as ideology [14].

The main problem of our time, according to the Nobel laureate I. Prigozhin, was stated by him in an interview with the "Expert" magazine in December 2000. Where is humanity heading: toward greater order or greater freedom (disorder, chaos)? "I am convinced that we are now approaching a point of bifurcation, after passing which humanity will find itself on one of several possible trajectories. The main factor is the information technology boom. We are approaching the creation of a "networked society" in which people will be connected with each other in a way never before. Is it good or bad? $<\ldots>$ With the growth of the planet's population, the probability of nonlinear microfluctuations associated with individual freedom of choice increases, since the number of players increases. On the other hand, as people are increasingly connected by networks, the opposite effect may appear: the imperatives of the united collective will suppress individual freedom of choice". "The paradox of I. Prigogine about freedom" is that both opposite tendencies are manifested simultaneously and often in relation to the same subjects of social action, as concerns mainly developed countries. Removing this problem and resolving the paradox leads to the emergence and mastery of an objective opportunity to overtake the crisis aggravation of global problems at least "one step". In any other case, under the conditions of the global crisis, the situation can be brought to a state characterized by the chess term "zugzwang", when any decision and action only leads to a worsening of the position. As noted by A.V. Erakhtin, the global crisis is fraught with the fact that there are too few options for getting out of it, and with a limited number of encouraging choices, one has to choose, making great sacrifices and introducing norms in order to strengthen control over the situation, options with a sharp restriction of the freedom of most people, which will inevitably cause strong resistance [15].

\section{Conclusions}

On the one hand, new technologies carry with them the threat of permissiveness, elevated to the ideal, and on the other hand, history shows that such projects are deprived of a stable social base and are rejected. As a result, a techno-humanitarian balance is formed, which previously ensured the solution of social crises at all previous stages of historical development and on the basis of its action, which took the form of a kind of law, we can already predict a successful solution to crisis problems in the future. "The higher the power of production and combat technologies, the more advanced means of cultural regulation are needed to preserve society. This generalized dependence was designated as the law of techno-humanitarian balance". People, as "weakly armed animals, were not subject to selection pressure that could develop strong and reliable prohibitions on killing, which are absolutely necessary for the survival of species with dangerous weapons. And when, with the invention of artificial weapons, new possibilities for murder suddenly opened up, the old balance between the relatively weak inhibition of aggression and the equally weak possibilities of murder was sharply violated". With the violation of the above-mentioned techno-humanitarian balance, its restoration was required. According to T.P. Berseneva, the main tool in this case is the ratio of the norm and the ideal as being and proper [16].

Concentration of attention on the main Challenge facing humanity and the search for an appropriate Answer allows us to direct the spectrum of efforts towards mastering the objective opportunity to overtake the crisis aggravation of global problems at least "one step". The ecological movement, the fight against the militarization of outer space, the idea of sustainable development, etc. correspond to such directions. Global challenges, of course, force us to reconsider all traditional ideas about freedom and responsibility, about morality and civilizational achievements of mankind. But the fact is that, as B. Gischbert 
writes, the evolutionary process does not have an "external designer", it is not controllable, and therefore all its characteristics cannot be subjected to conscious adjustment from our side, except for social (ethical, legal, etc.) norms and ideals, which, although in part, are still the products of our creativity [17].

\section{References}

1. D.A. Zhurenkov, Y.A. Trushkova, IFAC-PapersOnLine (2019) doi: 10.1016/j.ifacol.2019.12.548

2. S.S. Horujy, Culture and art 1, 25 - 40 (2016) https://doi.org/10.7256/22221956.2016.1.16838

3. S.S. Horujy, Philosophy and Culture 2, 268 - 274 (2016) https://doi.org/10.7256/19992793.2016.2.16982

4. V.P. Bransky, S.D.Pozharsky, I.G. Mikailova, S.V. Busov, M.R. Zobova, Issues of Philosophy. Scientific theory journal. Moscow 5, 56-66 (2017)

5. S.S. Horujy, Philosophy and Culture 2, 268 - 274 (2016) https://doi.org/10.7256/19992793.2016.2.16982

6. K. Shtekl, Church in Russia and abroad 36(3), 195-223 (2018) https://doi.org/10.22394/2073-7203-2018-36-3-195-223

7. P.B. Mikhailov, Bulletin of the Orthodox St. Tikhon Humanitarian University. Series $\begin{array}{llllll}\text { 1: Theology. Philosophy. Religious studies 71, 50-68 (2017) } & \end{array}$ DOI: $10.15382 /$ sturI201771.50-68

8. A.M. Mahler, Notebooks on conservatism 3, 131-138 (2019) DOI: $10.24030 / 24092517-2019-0-3-131-138$

9. S. Fufaev, Theological Bulletin 35(4), 38-71 (2019) DOI: 10.31802/2500-1450-201935-38-71.

10. J.K. Larcher, Questions of theology 1(2), 199-220 (2019) DOI: $10.21638 / \mathrm{spbu} 28.2019 .202$

11. A.V. Nesteruk, Journal of the Siberian Federal University. Series: Humanities 9(9), 2150-2183 (2016) DOI: 10.17516/1997-1370-2016-9-9-2150-2183

12. Chul Min Jun, Pacific Science Review 16, 156-166 (2014) https://doi.org/10.1016/j.pscr.2014.08.028

13. S.V. Busov, Izv. Saratov Univ. (N.S.), Ser. Philosophy. Psychology. Pedagogy 19(3), 246-250 (2019) DOI: https://doi.org/10.18500/1819- 7671-2019-19-3-246-250

14. A.V. Erakhtin, Historical and Social Educational Ideas 8(6/1), 133 - 136 (2016) doi: 10.17748/2075-9908-2016-8-6/1--6/1-133- 136

15. T.P. Berseneva, Man and culture 5, 35-46 (2013) DOI: 10.7256 / 23061618.2013.5.9526

16. G. van den Brink, International Journal of Systematic Theology 16(3) (2014) DOI: $10.1111 /$ ijst. 12053 